\title{
O MOVIMENTO “\#ELENÃO” E SEU APAGAMENTO DISCURSIVO SOB A CONTRANARRATIVA DO “\#ELESIM”
}

\section{THE “\#ELENÃO” MOVEMENT AND ITS DISCURSIVE DELETION UNDER THE “\#ELESIM” CONTRARY NARRATIVE}

\author{
Jamile Maria de Fátima da SILVA (UFPE) ${ }^{1}$
}

\begin{abstract}
RESUMO
Entendendo a língua como um construto de significados e significantes, e que produções discursivas são uma forma de construir narrativas através da produção de sujeitos, ideologicamente interpelados, adentramos à cena político-discursiva das eleições de 2018 com o intuito de proceder a uma investigação, à luz da Análise do Discurso de linha francesa, sobre a construção do contradiscurso que aviltou o êxito da maior manifestação social liderada por mulheres da história do Brasil. Metodologicamente, partimos da análise de enunciados retirados da rede social Facebook, onde ocorreu a maior concentração de apoio a essas narrativas. Com isso, objetivamos estabelecer a correlação entre os discursos antagônicos, com ênfase na contranarrativa despótica e antidemocrática, formada em torno do enunciado "EleNão", a qual condicionou o desfecho das manifestações de 2018, demonstrando, assim, como se deu o processo de (re)significação que reavivou condutas discriminatórias, as quais, até então, pensava-se estarem obsoletas, mas foram reintroduzidas no coletivo nacional. Para tanto, no que diz respeito à construção dos sentidos, memória e sujeito, reportamo-nos a Pêcheux (2010), com reflexões em Courtine (2006), Brandão (2004) e Grigoletto (2005). A partir das análises e verificações, percebe-se a influência ideológica condicionante nos arranjos enunciativos dos sujeitos, resultante da construção de sentidos que, intermediada pelas condições históricas, figuraram como uma nova materialidade discursiva que se formou diante das disputas das eleições 2018.
\end{abstract}

PALAVRAS-CHAVE: Análise do Discurso (AD); movimento \#EleNão; sujeito; contradiscurso.

\begin{abstract}
Understanding language as a construct of meanings and signifiers, and that discursive productions are a way of constructing narratives through the production of subjects, ideologically challenged, we enter the political-discursive scene of the 2018 elections in order to proceed with an investigation, to in light of the Discourse Analysis of the French line, on the construction of the counter-speech that debased the success of the largest social demonstration led by women in the history of Brazil. Methodologically, we started from the analysis of statements taken from the Facebook social network, where there was the greatest concentration of support for these narratives. With this, we aim to establish the correlation between antagonistic discourses, with emphasis on the despotic and anti-democratic counter-narrative, formed around the statement "Ele Não", which conditioned the outcome of the 2018. Thus, demonstrating how this process of revived discriminatory behaviors. Therefore, to the construction of the senses, memory and subject, we refer to Pêcheux (2010), with reflections on Courtine (2006), Brandão (2004) and Grigoletto (2005). From the analyzes and verifications, it is possible to perceive the ideological conditioning influence in the enunciative arrangements of the subjects, resulting from the construction of meanings that, intermediated by historical conditions, figured as a new discursive materiality that was formed in the face of the 2018 election disputes.
\end{abstract}

KEYWORDS: Discourse Analysis (AD); \#EleNão movement; subject; counter-speech.

\footnotetext{
${ }^{1}$ Mestranda em Linguística pela Universidade Federal de Pernambuco - UFPE. Contato: jamile.rhad@gmail.com
} 


\section{INTRODUÇÃO}

As eleições de 2018 configuraram um grande marco na historiografia das disputas presidenciais no Brasil. O cenário político foi tomado por intensos protestos contra, e a favor, dos pleiteantes ao cargo de presidente da república. Marcados por discursos inflamados e condicionados ideologicamente, os embates políticos giraram em torno de uma série de declarações polêmicas, as quais desencadearam várias manifestações de repúdio.

O maior e mais importante ato de protesto que se formou durante esse período foi o movimento "EleNão". Tal ato exerceu grande influência no cenário eleitoral. O movimento de iniciativa feminista ficou conhecido nacional e internacionalmente, mobilizando milhares de pessoas a se posicionarem contra o discurso machista e discriminatório de um dos principais candidatos na disputa à presidência, Jair Messias Bolsonaro.

A partir disso, propomos, neste artigo, entender como um movimento de tamanha magnitude e importância foi atenuado por uma contra narrativa autoritária e preconceituosa, forjada por conservadores e apreciadores do discurso de Bolsonaro. Para tanto, buscamos avaliar como a correlação existente entre a produção do enunciado "Ele Não" - e as variações opostas que ocorreram a partir dele - foram responsáveis pelo desfecho das eleições 2018.

Pautamos este trabalho nos pressupostos teóricos da Análise do Discurso, vertente que nos permite analisar as condições de produção, pelas quais a materialidade linguística foi construída. Por meio de retomadas do pré-construído no imaginário coletivo, buscamos identificar as posições-sujeito, formadas no contradiscurso, responsáveis pelo processo de ressignificação e refração dos objetivos almejados. Diante disso, identificar o lugar de onde falam os que gritam "EleNão" e o daqueles que respondem "EleSim" é de salutar importância para chegarmos ao resultado de nossas análises. Entendemos que a análise do discurso nos fornece um campo fecundo de investigação teórica, uma vez que, por meio dessa vertente, é possível traçar um paralelo entre linguagem, materialidade histórica e fenômenos linguísticos.

Partindo de vieses pecheutianos, evocamos um olhar analítico sobre as escolhas discursivas movidas através do ideológico, as quais incidem diretamente sobre as formas de relacionar-se dos sujeitos, sob a ótica de dominação e controle.

Dessa forma, nossas considerações foram organizadas em 04 (quatro) seções. Na primeira, centralizamos as discussões na construção do significar, através da memória e de seus efeitos na formação do sujeito político, guiadas por perspectivas de alguns dos aportes teóricos da Análise do Discurso.

$\mathrm{Na}$ segunda seção, apresentamos os percursos metodológicos seguidos para alcançarmos os resultados deste estudo; exploramos, brevemente, a noção de enunciado e o funcionamento da ideologia no interior da linguagem, bem como focamos em discursos de pessoas públicas, para melhor entendermos a dimensão que essas narrativas desenvolveram no cenário político-eleitoral.

A terceira seção traz uma abordagem geral do movimento "EleNão" e a cena antagônica protagonizada pelo "EleSim". A intenção é situar o leitor diante do cenário formado nas eleições de 2018 e, dessa forma, enfatizar a articulação com os conceitos epistemológicos nos quais este artigo se funda.

$\mathrm{Na}$ quarta e última seção, traremos a análise do corpus, juntamente com as considerações que incidem sobre os recortes selecionados. Por conseguinte, finalizamos nossas discussões com algumas considerações de como as produções dos discursos são e estão, a todo tempo, ideologicamente marcadas em diferentes posições sociais, podendo, pois, desembocar em representações distorcidas da realidade.

\section{Análise do discurso: percursos teóricos na formação de sentido, sujeito e memória}

Quando as tensões políticas da década de 60 tomavam conta do cenário mundial, e a palavra revolução ecoava em vários segmentos sociais, a ciência da linguagem lançava um novo 
olhar sobre a forma de conceber a língua. Passaram, a partir daí, a vigorar os postulados da Análise do Discurso de linha francesa (doravante AD), a qual emerge frente à necessidade de se trabalhar com a produção de sentidos na sociedade por meio da linguagem.

Influenciada por aportes teóricos do pensamento marxista, em conjunto com a psicanálise, a AD figura como a vertente que traz, para o centro das discussões linguísticas, a presença do sujeito em articulação com seu meio social. O externo passa a ser tomado como fator indispensável à produção de sentidos e às condições de produção do discurso. Esse entrelace regula a materialidade histórico-discursiva e tece os novos rumos de uma teoria que, embora incipiente, desvenda novos caminhos para abordar a língua. Um dos principais articuladores da teoria, Michel Pêcheux, numa releitura do estruturalismo, postula que:

\begin{abstract}
O sentido de uma palavra, de uma expressão, de uma proposição, etc., não existe "em si mesmo" (isto é, em sua relação transparente com a literalidade do significante), mas, ao contrário, é determinado pelas posições ideológicas que estão em jogo no processo sócio-histórico no qual as palavras, expressões e proposições são produzidas (isto é, reproduzidas). (PÊCHEUX, 1988, p.146)
\end{abstract}

Segundo Pêcheux (2010), as concepções dos sentidos são efetivadas em consonância com os sujeitos sustentados pela memória discursiva, os quais mantêm ou rompem com o "preestabelecido", e pela ideologia, orientadora de tal processo.

Entende-se que o sentido, segundo Brandão (2004), é algo produzido historicamente. É, pois, fruto de narrativas compartilhadas entre os sujeitos, que dotam de significação a formação discursiva (FD) dos falantes; esta, por sua vez, consiste na interlocução dos discursos, fazendo com que eles sejam, ou não, validados dentro de um meio interacional.

Pêcheux (2010) diz ser discurso o efeito de sentido construído por locutores, em um jogo de articulação entre língua e história para, assim, significar as coisas. Logo, a produção de um discurso depende do processo constitutivo e produzido entre os falantes, fazendo com que toda a materialidade discursiva seja produto resultante da interlocução.

São as redes de relações interacionais que determinam a formação de um processo discursivo, influenciando, por conseguinte, na construção dos sentidos. Assim, entendemos que "o processo de produção de um discurso é representado pela rede de relações que afetam os domínios semânticos previamente colocados em evidência" (PECHÊUX, 1997b, p.147); domínios estes que são expostos por meio da memória social inscrita em práticas.

Ao evocarmos a conceituação pecheutiana de memória discursiva, para estudos da construção do sentido, admitimos, tal qual postula a $\mathrm{AD}$, que os eventos históricos se materializam no discurso por meio de retomadas de elementos pré-construídos: paráfrases, deslocamentos ou desdobramentos do real histórico. A memória "é necessariamente um espaço móvel de divisões, de disjunções, de deslocamentos e de retomadas, de conflitos de regularização [...]. Um espaço de desdobramentos, réplicas, polêmicas e contra discursos" (PÊCHEUX, 2010, p. 56).

Diante disso, as redes de memória, que circundam os processos discursivos, ocupam um espaço que se desloca frente aos acontecimentos; é o lugar de restabelecimento dos discursos já ditos, podendo estes serem ressignificados ou adequados à situação presente, produzindo, assim, uma teia de novos significantes. Elas operam no processo de interpelação dos sujeitos, refletindo a carga ideológica que está para além da memória. Ou seja, inscrevem as tomadas de posição e as vinculações ideológicas dos sujeitos, no interior de suas escolhas linguísticas, constitutivas dos "processos discursivos" (PÊCHEUX, 1997, p.161).

Tais processos são responsáveis pela estruturação da memória coletiva e operam diretamente na atuação das instituições, as quais, por sua vez, remetem à ideologia presente dentro de suas inscrições discursivas. Assim, o que está socialmente inscrito nas arestas da sociedade são frutos de posições previamente condicionadas, mantenedoras e reguladoras de interpelações ideológicas, pelas quais os sujeitos moldam seus dizeres, condutas e atitudes. 
Para a AD, a ideologia é o vetor condicionante das ações do sujeito no seio social. É através dela que se produzem e se mantêm as diferenças necessárias ao funcionamento das relações sociais. "O sujeito da $\mathrm{AD}$ não é o indivíduo, sujeito empírico, mas o sujeito do discurso, que carrega consigo marcas do social, do ideológico, do histórico e tem a ilusão de ser a fonte do sentido" (GRIGOLETTO, 2005, p. 1). Ele passa pelo conceito althusseriano, defendido por Pêcheux (1997), de assujeitamento ideológico, no qual "a ideologia interpela indivíduos em sujeitos" regulando, assim, suas escolhas, seus valores e suas atitudes dentro do campo social; não podendo, pois, o processo de contradição/ruptura, no qual os sujeitos estão inclusos, dar-se fora dos pilares ideológicos.

Para Pêcheux (1997), a ideologia, juntamente com a linguagem, são parâmetros normatizadores das relações discursivas; atuam como fios condutores que posicionam o "eu" em relação ao Outro, fazendo com que estes se reconheçam ideologicamente dentro de determinados grupos ou formações sociais, sendo que "o centro da relação não está nem no eu nem no tu, mas no espaço discursivo criado entre ambos" (BRANDÃO, 2004, p.76).

Ao investigar o funcionamento da ideologia no interior da linguagem na $\mathrm{AD}$, Pêcheux (1975) busca compreender como a materialidade discursiva, imagens, gestos, expressões, dentre outros recursos linguísticos ou extralinguísticos, operam na construção de sentido criados/recriados pelos "sujeitos-falantes", e de como estes se tornam "sujeitos de seus discursos".

Para essa questão do significar através da linguagem, um dos principais pontos abordados por meio da Análise do Discurso Francesa remete à abordagem das discussões de ordem política no discurso, tanto pelo contexto da época quanto pelo propósito emergencial de atribuir à língua questões de cunho analítico que reflitam sobre os desdobramentos ideológicos presentes em classes sociais, grupos, partidos ou organizações governamentais. Assim, o discurso político logo tornou-se, segundo Courtine (2006, p. 60), "muito rapidamente o principal objeto da análise do discurso".

Courtine postula que "o discurso político é um lugar de memória” (COURTINE, 2006, p. 88). Segundo esse autor, o "discurso é geralmente definido como um enunciado emitido sob condições ou produções definidas" (2006, p. 65); logo, analisar a materialidade discursiva a partir de seu imbricamento histórico torna-se crucial para a AD.

Ao concebermos discurso como uma sucessão de enunciados situados histórica e culturalmente, instauramos, para o método de análise em pesquisas com $\mathrm{AD}$, que a materialidade linguística seja observada em correlação com o externo. Para isso, Foucault (2008) estabelece quatro passos para se trabalhar com a "função enunciativa". São eles: o referencial, a posiçãosujeito, o campo associado e a existência material.

Para o seguimento metodológico aplicado neste estudo, utilizamos em nossas premissas as características para identificação de enunciados propostas por Foucault (2008). Em seguida, passaremos a observar as variantes/variações que ocorrem a partir do enunciado "EleNão" no ambiente virtual onde se apresenta.

Partindo, pois, das afirmações foucaultianas, admitimos que nosso objeto estabelece os quesitos necessários às adequações metodológicas do estudo com enunciado, uma vez que: ao atribuir sentido e valor de verdade, com argumentos que ratifiquem o posicionamento de que o candidato Jair Bolsonaro seria uma ameaça aos direitos das mulheres, ele estabelece coexistência com seu referente; ao identificar e ter socialmente marcadas as identidades e as posições históricas e ideológicas daqueles que o enunciam, nosso objeto faz jus aos seus sujeitos; no que tange ao campo social, verifica-se que o enunciado "EleNão" possui relações com o pré-construído ao buscar reafirmar posições que estão, ou deveriam estar, guardadas no imaginário social, sendo que o mesmo processo de busca pela memória é, também, utilizado na contra narrativa do "EleSim".

Desse modo, nossa materialidade versa sobre o próprio recorte linguístico, respeitando as adequações e transformações do tempo e espaço que ela ocupa, dadas as condições de produção de sua enunciação, tal qual afirma Foucault quando diz que "a enunciação é um acontecimento 
que não se repete; tem uma singularidade situada e datada" (FOUCAULT, 2008, p. 116). Neste artigo, o corpus é apresentado através de recortes que remetem a essa materialidade.

Nesta perspectiva, estudar o enunciado com vistas à heterogeneidade, que compõe as formações discursivas, as condições de produção, é admitir a presença da interdiscursividade como um dos principais pontos na (re)construção dos sentidos:

O interdiscurso de uma FD deve assim ser pensado como um processo de reconfiguração incessante pelo qual o saber de uma FD é conduzido, em função das posições ideológicas que esta FD representa em uma conjuntura determinada, a incorporar os elementos pré-construídos produzidos no exterior dela mesma, para gerar sua redefinição ou retorno; para suscitar também a retomada de seus próprios elementos, a organizar a repetição, mas também para lhe provocar, eventualmente, seu apagamento, esquecimento ou mesmo sua degeneração. $\mathrm{O}$ interdiscurso de uma FD, como instância de formação/repetição/transformação dos elementos do saber daquela FD, pode ser referido como aquele que rege o deslocamento de suas fronteiras. (COURTINE, 1984, p. 24)

Essa noção de interdiscurso nos impele, enquanto analistas, a debruçarmo-nos não só sobre uma única formação discursiva, mas sim depreender o lugar da memória proveniente do entrecruze de diferentes FDs.

Para tanto, o foco de abordagem deste estudo recai sobre polarização de discursos antagônicos que permearam a cena política do movimento "Ele Não" versus o "Ele Sim", visando, desse modo, analisar a construção de interpelação ideológica dos sujeitos dentro de ambas as mobilizações, através dos enunciados "\#elenão", "\#elesim” e suas variações.

A busca pela materialidade linguística foi feita através do uso das hashtags ${ }^{2}$, que figuraram como impulsionadores discursivos da cena política dos dois movimentos, as quais, segundo o site Época (2018), reportaram-se, principalmente: “a \#elenão, com 1 milhão de menções, \#elenunca, com 390 mil, e a \#elesim, mobilizando cerca de 284 mil tuítes.”.

\section{Do \#EleNão ao \#EleSim": militância, protesto e ressignificação}

O movimento "\#elenão" foi uma mobilização político-apartidária, criada inicialmente por mulheres, ${ }^{3}$ que ocorreu no ano de 2018 em meio à corrida presidencial brasileira, tendo como principal objetivo impedir a eleição do então candidato Jair Messias Bolsonaro, atual presidente do Brasil, por suas declarações machistas, racistas, homofóbicas e misóginas, proferidas durante o decurso de sua campanha eleitoral.

Segundo Céli Regina Jardim Pinto (2019) ${ }^{4}$, professora do departamento de História da Universidade Federal do Rio Grande do Sul (UFRGS), "A manifestação \#EleNão em repúdio ao candidato a presidente Jair Bolsonaro [...] foi a maior manifestação de mulheres na história do Brasil". O movimento, que ganhou as ruas de várias cidades, dentro e fora do território nacional, foi impulsionado através das redes sociais e teve grande repercussão no meio midiático.

A princípio, o movimento foi organizado em forma de 'grupo' através de uma fanpage na rede social Facebook, intitulada "Mulheres Unidas Contra Bolsonaro - MUCB", 5 a qual logo atingiu a marca de 2 milhões de seguidoras com poucas semanas de criação, chegando a ter uma página

\footnotetext{
2"As hashtags surgiram em 2007, no Twitter, como um recurso que permite o agrupamento de mensagens em torno de um mesmo tema. [...]. Esse recurso se popularizou entre as comunidades virtuais e ultrapassou o ambiente da internet, sendo utilizada atualmente em outros ambientes e por diversos setores da sociedade, assumindo diferentes funções" (ALVES, 2017, p. 13)

3 Posteriormente à criação do grupo, alguns homens que se identificaram com a causa aderiram, também, ao movimento.

4 A professora proferiu a afirmação em uma entrevista concedida ao site https://www.bbc.com/portuguese/brasil45700013, em 30 de setembro de 2019.

${ }^{5}$ Atualmente, a página redefiniu o nome para Mulheres Unidas Com o Brasil, mantendo as iniciais MUCB.
} 
específica de MUCB para cada região do país. Segundo reportagem da revista Época (2019), o uso da hashtag \#EleNão "contabilizou mais de 1,6 milhão de menções contrárias e a favor do candidato à Presidência da República pelo PSL, Jair Bolsonaro, no Twitter". A mobilização logo ultrapassou os limites da rede e se materializou tanto nas ruas do Brasil quanto em alguns países do exterior em forma de protestos, com data e hora previamente definidas.

A ideia principal do movimento era a de conscientizar as mulheres, independente de credo ou posicionamento político, de que a figura do candidato em questão era uma ameaça aos valores básicos, e que sua eleição poderia significar um retrocesso aos direitos já adquiridos e aos que elas ainda estariam por adquirir. Porém, os enunciados e a argumentação discursiva proferidos em desfavor do candidato passaram a ser ressignificados dentro das condições de produção de um campo semântico de oposição político-ideológica, responsável por redimensionar o sentido empregado às mobilizações de 2018.

Embora as manifestações tenham sido de cunho apartidário, a polarização política esquerda versus direita -, propositalmente inserida no cenário das interlocuções discursivas, transformou as reivindicações em pautas antagônicas. Logo, as demandas reivindicadas pelas/os integrantes do grupo MUCB era em prol de uma eleição limpa, cujos candidatos se pautassem, primordialmente, no respeito às diferenças, independente do partido ao qual pertencessem. Todavia, as queixas desses ativistas passaram a ser "vistas" como um jogo político de esquerda, cujo único intuito era desestabilizar o candidato do PSL. O movimento teve, assim, suas exigências distorcidas por uma formação discursiva contrária aos seus reais objetivos.

As/os militantes das manifestações "EleNão" exigiam uma disputa política pautada no recorte de gênero, com o intuito de que as reflexões acerca do machismo social fossem pontos primordiais dos pleiteantes ao cargo de futuro presidente do Brasil. Desde o início da organização do grupo, os membros se colocaram como apartidários, exigindo que os direitos à dignidade e igualdade das mulheres fossem respeitados. Entretanto, apesar dos números, do alcance midiático e da participação de várias personalidades influentes no meio artístico e político, as mobilizações não obtiveram o resultado desejado, e o candidato a quem se pretendia derrotar nas ruas foi eleito presidente do Brasil.

A narrativa que ocasionou a vitória das eleições a Jair Bolsonaro girou em torno da campanha, cujo objetivo definido era o de impedir a reeleição, não de um candidato da oposição, mas sim de um único partido: o PT (Partido dos Trabalhadores). Assim, a atmosfera política que lastreou as eleições 2018, no Brasil, foi resumida a marcas de discursividades antagônicas; "um partido político é distinto de outro por sua língua, é pelo seu discurso que ele é reconhecido, é o seu discurso que as pessoas aderem, é o seu discurso que é repetido" (COURTINE, 2006, p, 68); assim, os argumentos do movimento "EleNão" foram reduzidos, pejorativamente, como sendo pautas esquerdistas e de reivindicações partidárias. Os protestos passaram a ser difundidos em publicações na internet como uma campanha eleitoral pró-PT e de ordem puramente feminista.

\subsection{O sujeito ideológico e o silenciamento do dizer}

A relação estabelecida entre os sentidos que se formam no processo de interlocução discursiva é fruto de compartilhamentos simbólicos evocados pelos sujeitos sempre que estes enunciam. A produção de um discurso é atravessada por determinações inconscientes, mantenedoras das ações sociais de sujeitos interpelados ideologicamente. Logo, a posição que um sujeito ocupa no processo do "dizer" refere-se à forma como o indivíduo, atravessado pela ideologia, captura as narrativas que são postas em seu caminho, moldando, pois, a sua intencionalidade e o curso das manifestações de sentidos na cena enunciativa por ele reproduzida.

É a partir da releitura de Althusser que o conceito de ideologia é incorporado nos vieses da AD de linha francesa. Posicionado dentro de um contexto marxista, Pêcheux elabora a noção de ideologia numa perspectiva de luta ideológica de classes, fazendo com que as condições de produção, reprodução e transformação, articuladas sobre a configuração econômica, migre do 
âmbito das ideias para a materialidade discursiva. Desse modo, a ideologia é posta no cenário da $\mathrm{AD}$, pelo autor, como "um conjunto complexo de atitudes e representações que não são nem 'individuais' nem 'universais' mas se relacionam mais ou menos diretamente a posições de classes em conflitos umas com as outras" (PÊCHEUX\&FUCHS, 1997, p.166).

Ainda em reformulação às proposições inicias de Althusser, e alçado em pilares da psicanálise lacaniana a qual traz uma relação entre ideologia e inconsciente, Pêcheux (1995) discute a noção de total de assujeitamento, uma vez que para ele "o não sujeito" é interpelado-constituído em sujeito pela ideologia (PÊCHEUX, 1997a), podendo não só reproduzir, mas também transformar as condições de produção. $\mathrm{O}$ autor postula que as intenções e efeitos de sentido aos quais se pretendem alcançar pelo locutor, estão atrelados ao âmbito das formações discursivas ao qual o sujeito pertence. Ou seja, as formações ideológicas recobrem as formações discursivas que sempre serão atravessadas por outras formações discursivas. Nisso consiste a ideia de interpelação do sujeito (a qual nos referimos em parágrafos anteriores): na identificação do sujeito no interior da FD que o constitui, fazendo com que haja um espaço para ele transitar, porém sempre no interior da FD. Esse espaço "vazio" é preenchido pela ideologia, a qual, segundo Orlandi (1999, p. 46), "é a condição para a constituição do sujeito e dos sentidos"; é ela, pois, quem dá forma ao sujeito.

Orlandi (1997) assevera que não só palavra, mas também o silêncio constitui forma de construir de sentidos. O modo pelo qual o sujeito utiliza um enunciado, em detrimento de outro, demonstra a presença do pré-construído por detrás de suas escolhas. Entendemos que, ao materializarmos discursivamente uma dada expressão, outra é silenciada. Assim, elaboramos ou reelaboramos as possibilidades de significantes, mediante o nosso desejo de significar.

Quando os que dizem "EleSim" se apropriam do mesmo escopo enunciativo dos que dizem "EleNão" para atacar seus "adversários", o intuito não é somente o de provocar um jogo de palavras antônimas, mas sim estabelecer um apagamento da narrativa que originalmente se apresenta nos discursos de seus opositores. Logo, essa junção proposital dos dois enunciados consiste em uma tentativa de provocar, ainda que parcialmente, uma falsa unicidade de sentido, em que um enunciado se sobrepõe ao outro com semelhanças gráficas, porém com sentidos opostos. Nesse entremeio, várias são as possibilidades de interpretação daquilo que é dito e, sobretudo, do não dito, pois, como cita Orlandi (1997, p. 49), “A linguagem empurra o que ela não é para o 'nada'. Mas o silêncio significa esse 'nada' se multiplicando em sentidos: quanto mais falta, mais silêncio se instala, mais possibilidade de sentidos se apresenta".

A materialização, aceitação e legitimação do enunciado "EleSim" obedece aos critérios de uma sociedade desigual com inclinações elitistas, machistas e discriminatórias contra minorias em geral. É uma condensação de dizeres implícitos que vêm reafirmar o pacto social de manutenção de poder por aqueles que o detêm.

\section{Reflexões analíticas do corpus: A (o)posição do contradiscurso. De onde falam os que dizem \#elesim?}

As análises abaixo remetem a amostras de funcionamento da ideologia no interior da linguagem. Entendemos que a teoria da AD pecheutiana, alçada em pilares marxistas, reforça a concepção de estruturação da sociedade através dos vieses ideológicos, sendo que "o sujeito político, aquele que enuncia um discurso, está realmente assujeitado a um todo de muitas condições de produção e recepção de seu enunciado. Ele é o ponto de condensação entre linguagem e ideologia" (COURTINE, 2006, p. 64). 
Vejamos:

Figura 1: para além da hashtag

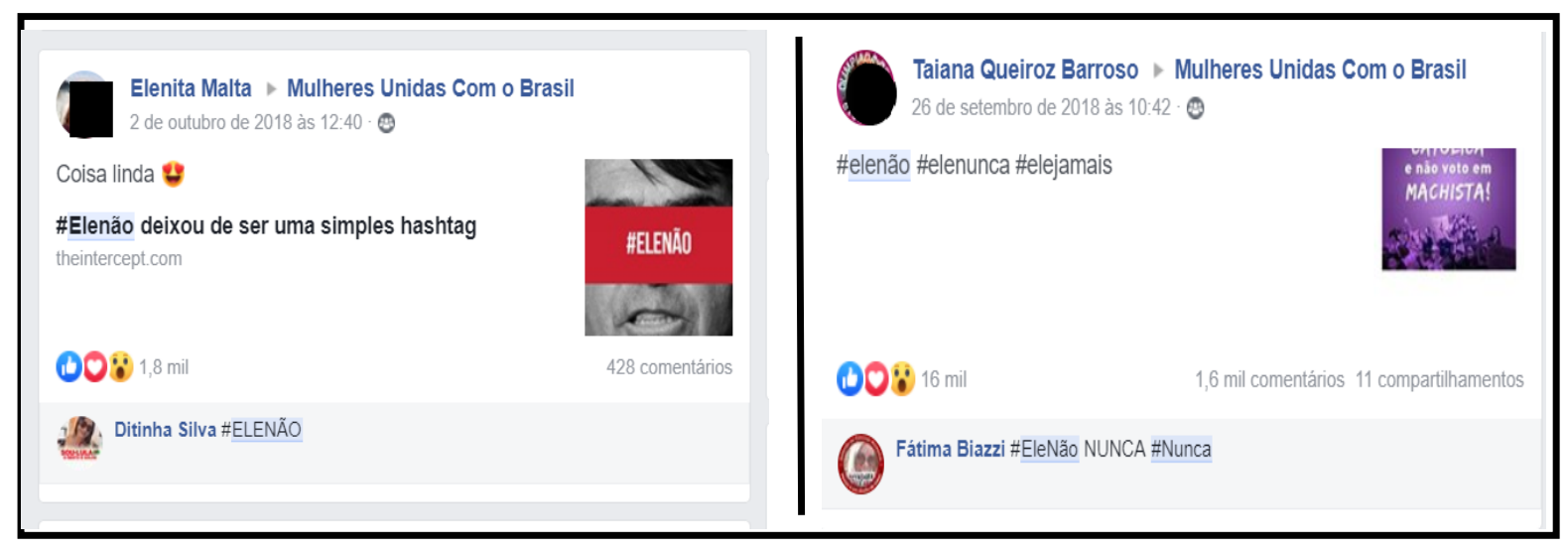

(Fonte:Facebook, 2018)

O recorte da figura 1 mostra uma sequência de duas publicações, apresentando a constatação de uma integrante do grupo MUCB, a qual faz referência à amplitude significativa do enunciado \#EleNão. Quando a participante do grupo MUCB diz que "o \#EleNão deixou de ser uma simples hashtag", ela ativa a percepção, simbolicamente, de que as manifestações de 2018 estão para além de um simples recurso cibernético; elas extrapolam o estrato virtual e passam a apregoar significância na estrutura social. A colocação da seguidora, conjugada com um post imagético de fundo, contendo a face de Bolsonaro em preto e branco coberta por uma tarja vermelha, com o enunciado \#EleNão sobreposto, alude ao desejo de se vetar o retrocesso que a eleição do candidato acarretaria. A cor vermelha escolhida para estampar alude ao partido dos trabalhadores, cuja cor representativa é o vermelho, e a intenção da ativação dessa memória diante do cenário eleitoral em questão.

A segunda parte da figura corresponde às variantes que o enunciado recebe: \#elenao, \#elenunca, \#elejamais, com o objetivo de reforçar o sentido de rejeição à idealização de um presidente com o perfil de Bolsonaro. São advérbios de negação que enfatizam a noção de desprezo à figura do candidato.

Dentre as adesões de maior repercussão ao movimento, a mais divulgada e de maior notoriedade foi a da cantora pop internacional Madonna (figura 2). Ela fez uma publicação em sua página pessoal no Instagram, onde reproduz o enunciado "\#EleNão" e incorpora a ele os seguintes elementos linguísticos: "vai nos desvalorizar", "vai nos oprimir "e "vai nos calar".

As semioses utilizadas pela artista em sua postagem seguem os padrões de contraste imagéticos encontrados nos posts brasileiros - a cor vermelha aplicada sobre o fundo preto e branco. Há, ainda, a utilização da fita adesiva sobre os lábios, sobreposta com a palavra "freedom" (liberdade), que remete à tentativa de silenciar o grito de protesto que o movimento fez ecoar: a ameaça de um governo autoritário e opressor que estaria por se formar, caso Bolsonaro fosse eleito. 
Acompanhemos:

Figura 2: apoio internacional

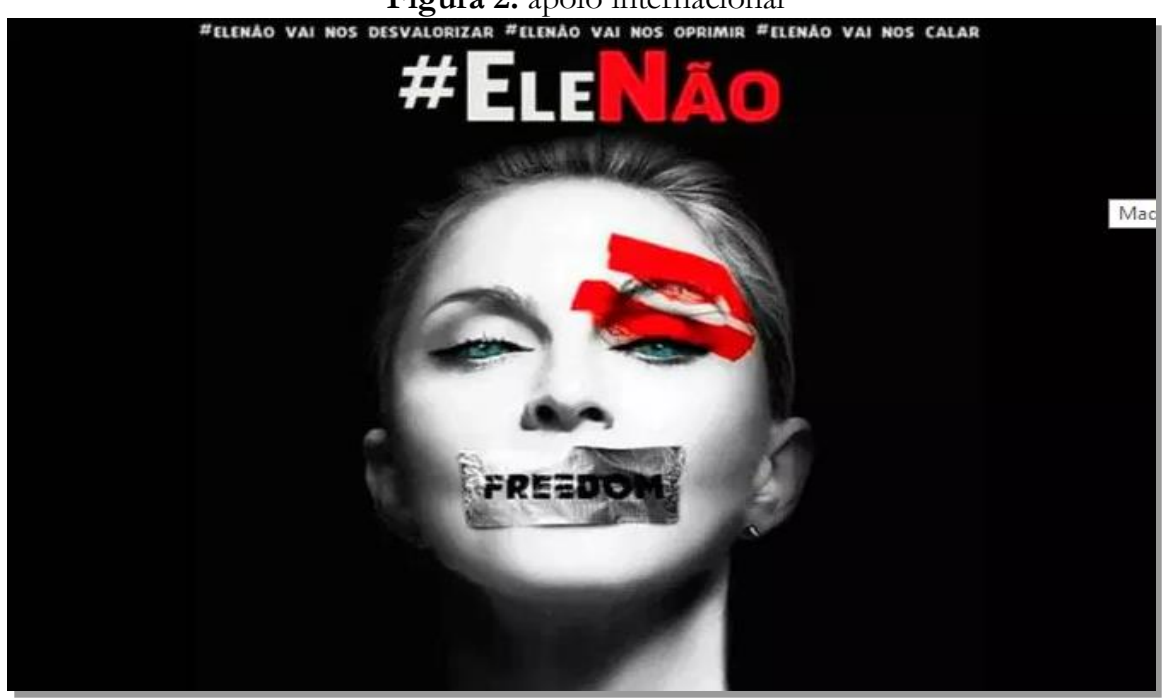

(Fonte: site Exame. - Publicado em 28 set)

Apesar de os atos contra Bolsonaro terem se espalhado dentro e fora do Brasil, o movimento perdeu força, ao passo que grupos e apoiadores da ideologia bolsonarista se levantaram contra a participação das figuras públicas que aderiram à campanha, deslegitimando suas vivências e, por conseguinte, seus discursos.

A estratégia dos apoiadores de Jair Bolsonaro de enfatizar a correlação do feminismo com o movimento não foi feita de forma fortuita, mas sim com o intuito de ativar, na memória do coletivo, pautas que o movimento feminista defende e que são vistas, ainda, com rejeição dentro da sociedade brasileira conservadora, como, por exemplo, a legalização do aborto, as liberdades sexuais, entre outras. Seguindo essa estratégia, não demorou muito para que a dicotomia mulheres de direita versus mulheres de esquerda tivessem sido implantada no centro das discussões, instigando a rivalidade e buscando minar a ideia de que o movimento representaria a opinião pública de todas as mulheres.

Para Brandão (2004), o sujeito é parte constituinte da sociedade ao mesmo instante que também é construído por ela. A autora retoma o conceito de "forma-sujeito" de Pêcheux, o qual diz que "a forma-sujeito é, portanto, o sujeito que passa pela interpelação ideológica ou, em outros termos, o sujeito afetado pela ideologia" (BRANDÃO, 2004, p. 81), para ratificar que, nos postulados da $\mathrm{AD}$, não é o sujeito empírico que interessa, mas sim o lugar social de onde esse sujeito fala.

Desse modo, em consonância com a ótica pecheutiana, entendemos que o silenciamento discursivo das manifestações de 2018 foi ocasionado por uma contra narrativa, proferida principalmente por sujeitos cuja ideologia remete a posicionamentos conservadoristas, misóginos e sexistas. Discursos estes que, por sua vez, foram legitimados por falas do presidenciável Jair Bolsonaro.

O principal alvo dos ataques foram as artistas que aderiram à campanha, pois, reconhecendo nelas o poder de influenciar a opinião pública, estas passaram a ter suas falas deslegitimadas pelos simpatizantes do candidato do PSL.

Observemos o exemplo abaixo: 
Figura 3: deslegitimação discursiva

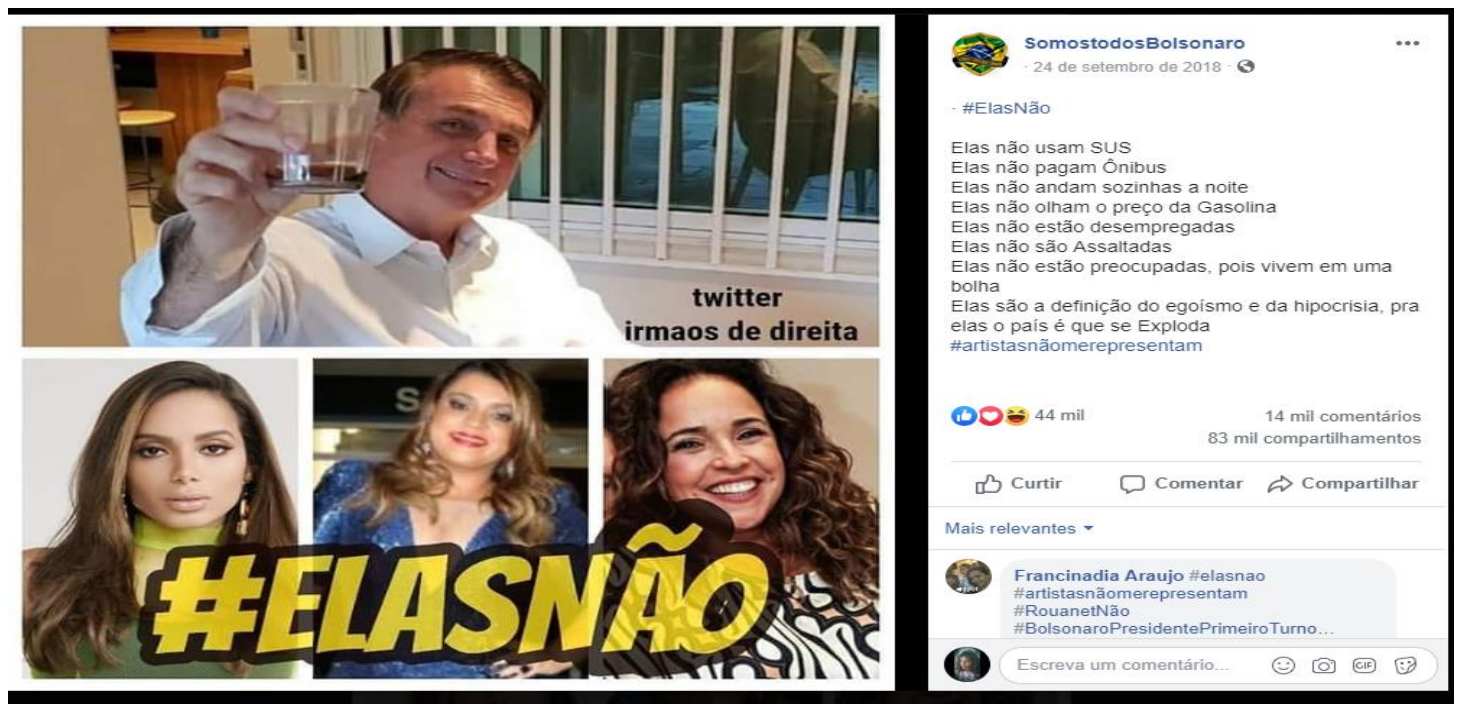

(Fonte: Facebook, 2018)

No recorte, as cantoras brasileiras Anitta, Preta Gil e Daniela Mercury são retratadas como mulheres que não deveriam opinar no cenário político, uma vez que suas vivências não são alinhadas à de mulheres comuns. Logo, a fala dessas personalidades que, segundo os apoiadores de Bolsonaro, nada saberiam sobre a vida de mulheres "normais", não poderia ser levada em consideração.

Através do uso da hashtag "ElasNão", variação do enunciado "EleNão", a imagem dessas artistas foi minimizada, desqualificada e reapresentada como de mulheres fúteis, alheias à realidade brasileira. É nesse ponto que enxergamos a grande participação do machismo, que passa a ser estruturado no seio do contradiscurso. À medida que a individualidade dessas mulheres é apagada, seus discursos são tomados como meros espetáculos midiáticos, caricatos e não dignos de apoio.

Outra forma usada para deslegitimar o movimento foram os efeitos de homogeneidade agregados à imagem das militantes. O discurso de que "são todas petistas" foi suficiente para alcançar aqueles que se mostravam indecisos diante das manifestações e conduzi-los para o lado oposto:

Figura 4: efeitos da interdiscursividade

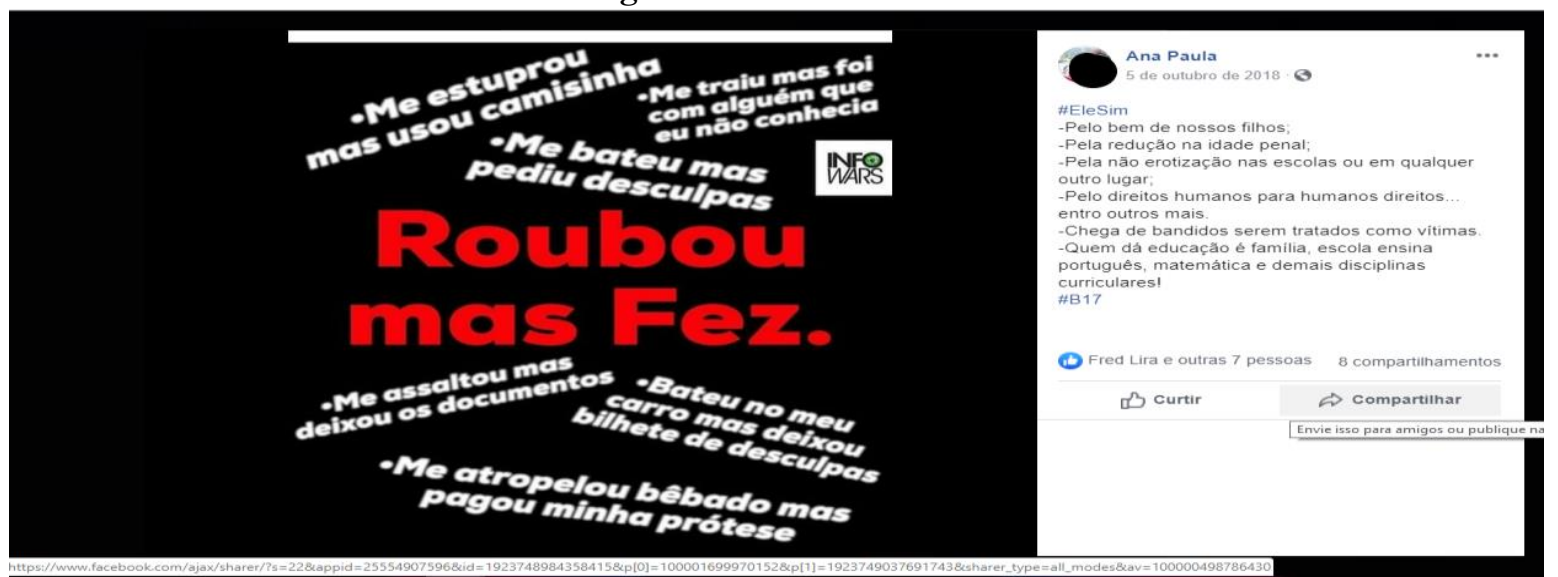

(Fonte: Facebook2018)

No post acima, vemos que a interdiscursividade construída pela mídia em relação ao Partido dos Trabalhadores é usada para ativar os efeitos de memória, por meio de enunciados dispostos a criar uma analogia semântica de descrédito com o qual se pretende vincular a imagem 
construída do PT: "aquele que rouba, mas faz". Isso põe uma cisão social, em que as escolhas do voto deveriam ser, pois, baseadas entre "Nós" e "Eles", os honestos versus os corruptos. Desse modo, a expressão \#EleSim é usada de forma a figurar como opositiva ao enunciado \#EleNão, não apenas no eixo sintagmático, mas, sobretudo, nas escolhas dos sentidos que apresentam posições ideológicas distintas.

\section{Apontamentos finais}

Por meio da observação do jogo enunciativo-político que se formou durante as eleições de 2018, foi possível inferir que o movimento \#EleNão, apesar de ter sido um ato de grande amplitude, foi abafado pelos ataques da narrativa contrária de grupos ultraconservadores movidos por interferência das refrações ideológicas que recaem sobre o social. O sentido do enunciado \#EleNão foi ressignificado diante de narrativas estereotipadas e regidas pela formação do senso comum, afloradas pelo discurso contrário que destacou, claramente, os papéis que os sujeitos da sociedade brasileira ocupam frente à responsabilidade de garantir os direitos e deveres de um corpo social igualitário.

É importante frisar que o discurso movido por distorções, negacionismo histórico e apagamento da memória do vivido é algo que induz à formação de governos totalitários, cujo principal objetivo é transformar o experenciado em um lugar de esquecimento, para, assim, dar continuidade a novas formas de opressão. Através das distorções de significados em que o efeito de sentido, incluindo os silêncios, foram direcionados para concepção de uma nova materialidade discursiva, percebeu-se como os sentidos foram construídos de modo a opor-se ao enunciado inicial, fortalecendo a narrativa de apoio ao discurso conservador e silenciando às reivindicações originais.

\section{REFERÊNCIAS}

ALVES, Lucy. O funcionamento discursivo das hashtags pela/na tv. 2017. $122 \mathrm{f}$.

Dissertação (mestrado em letras) - Universidade Federal de Pernambuco, Recife, 2017.

Disponível em: https://repositorio.ufpe.br/handle/123456789/29672. Acesso em: 09/08/2019

BRANDÃO, Helena. Introdução à Análise do Discurso. 2. ed. rev. Campinas: Editora da Unicamp, 2004.

FOUCAULT, Michel. A arqueologia do saber. Trad. Luis Felipe Baeta Neves. 2. ed. Rio de Janeiro: Forense-Universitária, 2008.

COURTINE, Jean-Jacques. Metamorfoses do discurso político: a deriva da fala pública. Trad. Nilton Milanez, Carlos Piovezani Filho. São Carlos: Claraluz, 2006.

. (2016). Definição de orientações teóricas e construção de procedimentos em

Análise do Discurso. Policromias: Revista de Estudos do Discurso, Imagem e Som, Museu Nacional, UFRJ, n. 2, v. 1, p.14-35.

GRIGOLETO, Evandra. Do lugar social ao lugar discursivo: o imbricamento de diferentes posições-sujeito. In: SEMINÁRIO DE ESTUDOS EM ANÁLISE DO DISCURSO, 2. 2005 , Porto Alegre. Anais eletrônicos. Porto Alegre: UFRGS, 2005. Disponível em: http://www.ufrgs.br/analisedodiscurso/anaisdosead/2SEAD/SIMPOSIOS/EvandraGrigoletto .pdf. Acesso em: 07/08/2019.

ORLANDI, Eni, Pulcinelli. As Formas do Silêncio: no movimento dos sentidos. 4. ed. Campinas: Editora da Unicamp, 1997. 
Campinas: Pontes, 1999.

ORLANDI, Eni Puccinelli. Análise de discurso: princípios e procedimentos.

PÊCHEUX, M. \& C. FUCHS (1975) A propósito da análise automática do discurso: atualização e perspectivas. In F. Gadet e T. Hak (orgs) Por uma análise automática do discurso: uma introdução à obra de Michel Pêcheux. Trad. Bethânia Mariani et al. Campinas: Editora da Unicamp, 1997.

PÊCHEUX, Michel. Semântica e discurso: uma crítica à afirmação do óbvio. Trad. Eni Pulcinelli Orlandi et al. Campinas: Editora da Unicamp, 1997a.

. Análise Automática do Discurso. In: GADET F.; HAK, T. (Orgs.). Por uma Análise Automática do Discurso: uma introdução à obra de Michel Pêcheux. Trad. Eni P. Orlandi. Campinas: Editora da Unicamp, 1997b.

2009 (1988). Semântica e Discurso. 4. ed. Campinas: Editora da Unicamp.

O papel da memória. In: ACHARD, P. et al. O papel da memória. Trad. José

Horta Nunes. 3. ed. Campinas: Pontes, 2010.

\section{Sites}

Disponível em: <https://www.bbc.com/portuguese/brasil-45700013> Acesso em: 29/07/2019 às $21 \mathrm{~h} 40 \mathrm{~min}$

Disponível em: < https://epocanegocios.globo.com/Tecnologia/noticia/2018/09/movimentoelenao-atinge-mais-de-12-milhao-de-mencoes-contra-bolsonaro.html> Acesso em 06/08/2019 às $21 \mathrm{~h} 21 \mathrm{~min}$

Disponível em: < https://exame.abril.com.br/brasil/madonna-posta-imagem-de-apoio-aoelenao/> Acesso em 18/10/2020 às $21 \mathrm{~h} 16 \mathrm{~min}$

Submetido em 09/06/2020

Aceito em 22/09/2020 